The following is an author version of a paper submitted to Studies in Higher Education, which was accepted on February 26, 2019. This version of the paper is the submitted, rather than accepted, version, so may not reflect all changes adopted throughout the review and editing process. For the definitive published version, please go to https://doi.org/10.1080/03075079.2019.1590690

\title{
Citation:
}

Rose, H., Curle, S., Aizawa, I., \& Thompson, G. (2019). What drives success in English medium taught courses? The interplay between language proficiency, academic skills, and motivation. Studies in Higher Education. DOI: 10.1080/03075079.2019.1590690.

\section{What drives success in English medium taught courses? The interplay between language proficiency, academic skills, and motivation}

Heath Rose (corresponding author)

Department of Education, University of Oxford, Oxford, UK

Samantha Curle

Department of Education, University of Bath, Bath, $U K$

Ikuya Aizawa

Department of Education, University of Oxford, Oxford, UK

Gene Thompson

Department of Global Business, Rikkyo University, Tokyo, Japan

Correspondence: 15 Norham Gardens, Department of Education, University of Oxford, Oxford, United Kingdom, heath.rose@education.ox.ac.uk

Heath Rose is an associate professor of applied linguistics at the University of Oxford. He has published EMI-related work in journals such as Higher Education, and in his co-authored book Global Englishes for Language Teaching (Cambridge University Press, 2019).

Samantha Curle is a lecturer in applied linguistics in the Department of Education at The University of Bath. Her EMI-related research has recently appeared in journals such as Language Teaching and Journal of Asia TEFL.

Ikuya Aizawa is a researcher in the EMI Oxford research group at the University of Oxford. His EMI-related research focuses on Japan, and has most recently appeared in the journal Higher Education.

Gene Thompson is an associate professor in Rikkyo University's Department of Global Business, which offers one of the few bilingual business degree programs in Asia. His research has appeared in journals such as the Asia-Pacific Journal of Teacher Education and Innovation in Language Learning and Teaching. 
This article explores the relationship between course performance, English language proficiency, motivation, and academic language skills in an English medium instruction (EMI) university context. It analyses test and questionnaire data from 146 students from an EMI business program at a Japanese university, and follow-up interviews with seven students. Proficiency test and subject exam scores revealed that knowledge of English language and academic English skill were statistically significant predictors of success in EMI, suggesting that lower proficiency students require more targeted language support in order to increase their likelihood of success. A motivation measure did not correlate with higher grades, contradicting research in language learning contexts. Interview data uncovered the multi-faceted nature of 'success in EMI' suggesting that students see success as a combination of final grades, lecture comprehension, English language proficiency gains, and long-term career advancement.

Keywords: Japan; English Medium Instruction; Proficiency; Motivation; English for Specific Purposes

\section{Introduction}

It is now well established that the phenomenon of English Medium of Instruction (EMI) is expanding at a rapid pace across the globe (Wächter and Maiworm 2014; Macaro et al. 2018; Macaro 2018). English is becoming universal in many academic disciplines, and internationalization is being realized via 'Englishization' of the curriculum within many higher education institutions. This switch in medium of instruction means that English has shifted from being taught as a foreign language alongside other school subjects to becoming an important educational language used for learning and teaching all academic subjects.

EMI is defined in this study as 'the use of the English language to teach academic subjects (other than English itself) in countries or jurisdictions where the first language (L1) of the majority of the population is not English' (Macaro 2018, 19). This definition captures the current context of Japanese higher education, where a series of recent government-funded policies has seen the rapid expansion of EMI at select universities (see Author and Other 2018; Author and Author 2018). The study presented in this paper aims to explore success in EMI, by examining the role of language proficiency, academic English skills, and language motivation in predicting content knowledge development. Student perceptions of success are also explored in follow-up interviews, to develop a more nuanced understanding of how these factors may interact.

\section{Background to the study}

\section{Driving forces behind EMI}

As a result of the increasing popularity of EMI, researchers (e.g. Galloway, Kriukow and Numajiri 2017; Hu, Li and Lei 2014) have proposed various driving forces behind this trend related to the potential enhancement of students' career opportunities. Consistent with English being seen as a language of prestige in $\mathrm{HE}$ and as a means to facilitate academic discourse (Morrison and Lui 2000; Smit 2010), two main benefits mainly revolve around the improvement of English language proficiency and the development of internationally-minded students and staff members. A widely purported benefit of EMI is that it kills two birds with one stone; in other words, students simultaneously acquire both English and content knowledge. Accordingly, EMI has 
been enthusiastically supported by many researchers (e.g. Brinton, Snow and Wesche 2003; Coleman 2006; Smit \& Dafouz 2012), who have argued that it offers students exposure to English when the negotiation of content knowledge also takes place, making it an ideal learning situation for learners to achieve both goals.

\section{Success in EMI}

Despite the various kinds of perceived benefits of EMI, there are different goals that EMI stakeholders aim to achieve. Educators often focus solely on the achievement of disciplinary knowledge. Costa (2012) for example, notes that EMI lecturers in the Italian HE context were mainly focused on teaching content knowledge, indicating that language outcomes were not on the agenda. In Sweden, Airey (2012) similarly reported that EMI was focused on content only and no language learning was expected, indicating that EMI success revolved around content knowledge development. In his investigation of EMI lecturers' view on the disciplinary language-learning expectations for university students, the lecturers did not think it was their job to teach language and did not feel comfortable correcting their students' English errors, suggesting that EMI is predominantly more attentive to content than to language learning. This contrasts with the aims for EMI, discussed in the previous section, which see EMI as a vehicle to achieve both linguistic and content knowledge.

In the context of the current study, the Japanese Ministry of Education, Culture, Sports, Science and Technology (MEXT) defines EMI as 'courses conducted entirely in English, excluding those whose primary purpose is language education' (MEXT 2015). Thus, in Japan too, EMI does not have an explicit aim to improve students' English knowledge, and mainly focuses on the transformation of content knowledge through English. The present study, therefore, examines this conceptualization of 'success in EMI' by examining student mastery of disciplinary knowledge.

Alongside global differences in the motivations and goals of EMI (Hamid et al. 2013), the ways in which programs are implemented differ due to contextualized educational needs. As higher education policies manifest in different ways and are still in their infancy in Japan (Author and Other 2018), little is known about how students as key stakeholders - perceive success in EMI. Accordingly, we aimed to explore these perceptions with respect to EMI in the Japanese higher education context.

\section{English language proficiency in EMI}

In order for students to acquire content knowledge sufficiently, numerous scholars (e.g. Leaver and Stryker 1997; Johnson and Swain 1997) have suggested that the level of students' English proficiency should reach a certain threshold level. Some research has advocated that in immersion contexts higher student English proficiency is achieved at no cost to their disciplinary learning (Turnbull, Hart and Lapkin 2001). Other research (e.g. Lin \& Morrison 2010; Evans and Morrison 2011) has shown that while students respond to linguistic challenges when transitioning into EMI due to language difficulties, this tendency is less apparent among more proficient learners of English. This suggests that students have different EMI experiences depending on their level of linguistic proficiency. For this reason, the current study focuses on this relationship, by exploring whether, and to what extent, proficiency predicts success.

In EMI contexts, studies examining the association between language proficiency and academic performance are scarce, mainly because previous research has largely collected indirect measures and participants' self-reports of their academic performance in EMI (Başıbeka et al. 2013). In one of the earlier studies that explored 
whether English language proficiency predicted academic success at an English medium university, Graham (1987) used students' grade point average (GPA) as a proxy for achievement. However, using this metric as a measure of academic performance can be methodologically problematic as course grades and GPAs reflect a variety of factors, such as completion of coursework, and often course attendance (Dafouz, Camacho and Urquia 2014). The present study, on the other hand, uses only scores of mid-term and final examination, which is more of a direct indication of students' academic content knowledge acquisition.

\section{English language proficiency as a predictor of academic success}

Numerous studies have examined the relationship between English language proficiency and academic success (see Cho and Bridgeman 2012; Johnson 1988; Martirosyan, Hwang, and Wanjohi 2015). As there is a dearth of research into this relationship in EMI contexts (Macaro et al. 2018), research has particularly focused on how TOEFL (Test of English as a Foreign Language) and IELTS (International English Language Testing System) scores predict the academic performance of international students studying in English speaking countries - results of which are contradictory.

Some studies have found a statistically significant positive association. For example, Light, $\mathrm{Xu}$, and Mossop (1987) found that TOEFL scores were positively correlated with the GPA scores of 376 international graduate students at a state university in New York. More recently, Huong (2001), Woodrow (2006), and Yen and Kuzma (2009) have also found significant correlations between academic performance and IELTS scores. Conversely, other studies (e.g. Krausz et al. 2005; Xu 1991) have found TOEFL scores to be an insignificant predictor of academic success. In 2010, Wongtrirat conducted a meta-analysis of 22 research studies that took place between 1987 and 2009. Results revealed that TOEFL scores did not significantly predict academic achievement (operationalised as either GPA or 'course completion'). Hill, Storch, and Lynch (1999) found that TOEFL scores were weakly correlated, but did not significantly predict academic achievement. They found similar results when examining academic success and IELTS scores. Similarly, no statistical relationship between IELTS and GPA was found by Kerstijens and Nery (2000).

These contradictory results have led to suggestions that other factors may play an important role. For example, researchers (e.g. Dimova, Hultgren, and Jensen 2015) have suggested that the 'preparedness' of students should be examined more closely, while it appears that academic support classes may help students interact with EMI content lectures (Chang, Kim and Lee 2017). In other words, skills beyond those assessed by standard L2 proficiency tests are likely to influence EMI performance. Accordingly, our study considers both English language proficiency and mastery of academic skill with respect to EMI success.

\section{Motivation}

EMI success may also be influenced by student motivation, with calls for research (e.g. Doiz, Lasagabaster, and Sierra 2014; Pokay and Blumenfeld 1990; Stoynoff 1997) to explore the relationship between learning content via the L2 and language learning motivation. The underlying reason is that more motivated students may self-select to take part in content study in English, and this motivation may play a role in their success. For this reason, our study also considers the effect of motivation on overall success in EMI study within its methodological design. 
Motivation research has a strong history in applied linguistics research, and has been conceptualized within various frameworks over the past decades with the L2 motivational self-system being the current prevailing framework (Dörnyei and Ryan 2015). The Ideal L2 Self, defined as an idealized future vision of the type of speaker one would like to become, has been found to be the most 'potent' measure of motivation in EMI contexts (Lasagabaster 2016, 328). This measure has been used in much research on language learning motivation in Japan (e.g. Taguchi, Magid, and Papi 2009), and thus was adopted in the current study.

\section{Design of the study}

The current study addressed the following questions:

(1) Does English proficiency predict success in EMI?

(2) Does language learning motivation predict success in EMI?

(3) Does academic language skill predict success in EMI?

(4) To what extent do motivation, academic language skill, and L2 proficiency predict success in EMI?

(5) How do students perceive success in EMI?

\section{Setting}

As EMI has been shown to be context-specific, a single case-study was chosen for the current study to eliminate context-related confounding variables affecting successrelated scores. An EMI course on the topic of International Business offered at a Department of Business Management at a university in Japan was chosen as the main site for data collection. This setting was deemed appropriate for the study because:

- The course was taken by predominantly Japanese domestic students, thus minimizing the effect of first language differences on success in EMI

- The course was taken in the students' second year, thus allowing them to become accustomed to university-style assessments, and minimizing the transition effects noted in previous research (e.g. Evans and Morrison 2011)

- All students simultaneously undertook an academic English skills development program, allowing us to explore the relationship between academic preparedness and success

- The International Business course was the first EMI class taken by the students in the programme, thus minimizing the effect of previous EMI experiences on success

- All students taking the course had completed a uniform curriculum in the 18 months preceding the class, minimizing the effect of different English language learning experiences at university level

- All students within the program took frequent language proficiency tests as part of the program structure, meaning we could obtain standardized measures of language proficiency taken at the same time by all participants

- All students attended the same lectures given by the same course lecturer, thereby minimizing the effect of different pedagogical approaches on success

\section{Data collection}

Data collection included the following research instruments and measures:

- A questionnaire, which included demographic details and items related to language learning motivation 
- Mid-term and end-of-term content test scores for the 'International Business' (IB) course

- A language proficiency measure (TOEIC)

- End-of-term scores for the 'English for Specific Purposes' (ESP) academic skills development course, which supports skill development for the IB class.

- Interviews with a subset of students $(n=7)$

In this study, success was measured using a final composite grade of students' International Business midterm and final examination scores. Other elements that contributed to course grades, including students' written reports and group business presentations were not used, as evaluation criteria for these assignments included other factors (e.g. participation and team-work) that were not targeted measures of content knowledge acquisition. Although this was a somewhat crude measure of success, these scores constituted the primary assessments for the course and represented measures of content knowledge mastery. These were supplemented with qualitative student interview data, as it was recognized that participants might perceive success as something more complex.

English language proficiency was measured as the highest TOEIC score that a student achieved within the academic year of 2017-2018. Consultation with the head of the English language program revealed that students may not excel on all test sittings, especially if they are satisfied with a previously achieved score. Thus, using the highest score was deemed a more suitable measure of proficiency than using the most recent test sitting. The mean TOEIC score was 769.4 ( $\mathrm{SD}=116.6)$, with the lowest score being 485 , and highest 980 . This placed students between CEFR levels of A2 to C1, with the majority of students falling into the B1 level, indicating that the majority were at the threshold of being independent users of the language.

Motivation (focusing on the Ideal L2 Self) was measured on a six-point Likert scale using four items (see Appendix A) from an adapted motivation questionnaire based on Iwaniec's (2014) study of motivation in Polish students. This questionnaire was deemed an appropriate measure as it has been used in a series of British Council English Impact studies in a wide range of contexts (e.g. Sheppard \& Ainsworth 2017), and also has been used in other recently published work (Alderson, Nieminen, and Huhta 2016).

Finally, a measure of students' academic language skill was operationalized using the students' grade scores from the English for Specific Purposes course, that is, the academic language support class for the International Business class. The ESP grades were a composite score derived from academic-related skills assessments including reading worksheets, note-taking worksheets, academic presentations and a written report, thus covered a range of academic activities. This grade was used to tease apart success in academic language-related preparedness from success in EMI studies, and to explore the relationship between the two. One limitation of using this measure is that it represents a school-specific and subjective measure of preparedness. However, it was deemed adequate for the purpose of this study as it is ecologically-valid, in that student success in this class is used within the program itself to determine students' readiness to undertake EMI.

\section{Participants}

A total of 159 second year students completed the motivation survey and agreed to share their TOEIC and test score data. However, due to missing data (e.g. no final test 
scores) for 11 students and the presence of two outliers, 146 responses were analysed in this study to address the first four research questions. In order to enhance the significance of the multiple regression findings and respond to research question five, follow- interviews were carried out with seven students. Although, the conclusions that can be drawn from these interviews are limited by the low number of students who volunteered to participate, these students (see Table 1) represent higher and lower L2 proficiency and have varying grades both for the academic skills preparation class (ESP) and EMI course (International Business). Thus, they provide some insight in the perceptions of success within the wider student population.

\section{[PLEASE INSERT TABLE 1 HERE]}

Table 1. Interview participants

\begin{tabular}{|c|c|c|c|c|}
\hline Name & Gender & TOEIC & IB Grade & ESP Grade \\
\hline Aoki & Female & 645 & C & B \\
\hline Fumizaki & Female & 900 & A & A \\
\hline Hishinuma & Female & 910 & B & B \\
\hline Hirota & Male & 790 & A & A \\
\hline Ro & Male & 975 & B & A \\
\hline Takagi & Male & 845 & A & A \\
\hline \multicolumn{7}{|c|}{ Yujima } & Male & 940 & A & S \\
\hline $\begin{array}{l}\text { Notes: Names are pseudonyms; IB }=\text { International Business Course; ESP = English for Specific Purposes Course; } \\
\text { pading scale ranges from S to F (S, A, B, C, F) where S represents the highest possible grade, and C the lowest possible }\end{array}$
\end{tabular}

\section{Procedures and data analysis}

The questionnaire was piloted with seven students who had taken the course during the previous year, and items were adjusted based on this feedback. Similarly, the semistructured interview protocol was piloted with two of these students for similar purposes. Questionnaires were completed by students in Week 8 of the 14-week course, and interviews were conducted at the end of the course after final examinations. To investigate research questions one to four, descriptive statistics were generated for questionnaire, test score, L2 proficiency measures, and motivation items, then regression analyses were carried out to explore the relationship between EMI success (the outcome variable) and L2 proficiency (RQ1); motivation (RQ2); L2 academic skill preparedness (RQ3). Finally, a multiple regression analysis was carried out to identify the extent to which these variables predicted EMI success (RQ4). To explore research question five, semi-structured interviews were carried out in a bilingual format with seven students. Transcripts were transcribed and translated by one of the researchers, and interviews were analysed to identify patterns in responses related to 'success in EMI'. 


\section{Results}

\section{Does English proficiency predict success in EMI?}

In order to answer research question one, simple linear regression was carried out to investigate the relationship between TOEIC and EMI examination (content) scores. Descriptive statistics are presented in Table 2, which show a wide range in both L2 proficiency $(\mathrm{SD}=116.6$, range $=495)$, and $\mathrm{EMI}$ examinations $(\mathrm{SD}=7$, range $=31)$. Neither variable was significantly skewed or kurtotic, and the data met all assumptions of regression. Simple linear regression showed a statistically significant relationship between TOEIC scores and content scores $\left(\beta=0.03 . \mathrm{F}(1,144)=51.2, p<0.001^{* * *}\right)$.

[PLEASE INSERT TABLE 2 HERE]

Table 2. Descriptive Statistics of TOEIC and Content Scores

\begin{tabular}{|c|c|c|c|c|c|c|c|c|c|c|}
\hline Variable & $n$ & mean & sd & median & $\min$ & $\max$ & range & skew & kurtosis & se \\
\hline TOEIC Score & 146 & 769.4 & 116.6 & 790 & 485 & 980 & 495 & -0.31 & -0.77 & 9.65 \\
\hline Content Score & 146 & 72.9 & 7.0 & 72 & 57 & 88 & 31 & -0.08 & -0.66 & 0.58 \\
\hline
\end{tabular}

The scatterplot in Figure 1 shows that there was a medium-to-weak positive linear relationship between the two variables, which was confirmed with a Pearson's correlation coefficient of $0.51(p<001 * * *)$. The slope coefficient for TOEIC scores was 0.03 which indicates that the content score increases by 0.03 for every point increase in TOEIC score. The $\mathrm{R}^{2}$ value was 0.257 , which means that $25.7 \%$ of the variance in content score attainment can be explained by a model containing only TOEIC scores (see Table 3).

\section{[PLEASE INSERT FIGURE 1 HERE]}

Figure 1. Scatterplot of Content Scores and TOEIC Scores

Table 3 also highlights the standardized Beta value $(\beta)$. This value $(0.51)$ indicates that for every one-standard deviation increase in TOEIC score, content scores increase by 0.51 standard deviations (i.e. increased by $3.54 \%$ ). To summarise, TOEIC scores statistically significantly predicted success as measured by content examination scores: the higher the TOEIC score, the higher the content score.

\section{[PLEASE INSERT TABLE 3 HERE]}

Table 3. Linear Regression Output TOEIC scores and Content scores

\begin{tabular}{|c|c|c|c|c|c|c|}
\hline & $\Delta R^{2}$ & $B$ & $S E B$ & Standardized $\beta$ & $t$ value & $p$ value \\
\hline Constant & 0.257 & 49.12 & 3.36 & & 14.60 & $<0.001^{* * *}$ \\
\hline TOEIC & & 0.030 & 0.004 & 0.51 & 7.15 & $<0.001^{* * *}$ \\
\hline
\end{tabular}

\section{Does language learning motivation predict success in EMI?}

Research question two explored the relationship between success in EMI (i.e. content scores) and motivation. Again, a simple linear regression was used to explore the variance in content scores in relation to the mean value of the questionnaire items related to the Ideal L2 self. The mean score of this variable was $3.4(\mathrm{SD}=1.1, \mathrm{SE}=0.09)$, with a median of 3 , and a range from 1 to 6 . Skewness (-0.08) and kurtosis $(-0.34)$ fell within the acceptable range of +1 to -1 (Hair et al. 2010); and all other regression assumptions were met. 
Simple linear regression showed a non-statistically significant relationship between language learning motivation and content scores $(\beta=0.4 . \mathrm{F}(1,144)=0.599, p$ $>0.05)$. The $\mathrm{R}^{2}$ value was -0.002 , highlighting negligible explanation of motivation in content scores $(0.2 \%$ of the variance). Table 4 echoes these finding as illustrated by the standardized Beta value of 0.064 ; content scores only increased by 0.06 for every one standard deviation increase in motivation scores. To conclude, motivation, as measured as the Ideal L2 Self, was not a statistically significant predictor of success in EMI, as measured by content examination scores.

\section{[PLEASE INSERT TABLE 4 HERE]}

Table 4. Linear Regression Output: Motivation (Ideal L2 Self) and Content Scores

\begin{tabular}{|c|c|c|c|c|c|c|}
\hline & $\Delta R^{2}$ & $B$ & $S E B$ & Standardized $\beta$ & $t$ value & $p$ value \\
\hline Constant & -0.002 & 71.54 & 1.88 & & 37.86 & $<0.001$ *** \\
\hline TOEIC & & 0.4 & 0.54 & 0.064 & 0.77 & 0.44 \\
\hline
\end{tabular}

\section{Does academic language skill (i.e. ESP grades) predict success in EMI?}

The relationship between success in EMI and students' academic language skill (i.e. English for Specific Purposes grade) was then explored in order to answer the third research question. The mean ESP Grade was $79(\mathrm{SD}=10, \mathrm{SE}=0.84)$, with a median score of 80. The lowest ESP grade was 49 and the highest was 98 (out of 100) giving a range of 49. The data was approximately normally distributed (ESP skewness $=-0.34$, kurtosis $=-0.54)$ with no outliers. The data met all the assumptions for regression.

There was a statistically significant medium positive correlation between success in EMI and ESP grades $(r=0.61, p<0.001 * * *)$, as illustrated in the scatterplot (see Figure 2). Thus, a positive increase in the ESP grade reflected a positive increase in the International Business content scores.

\section{[PLEASE INSERT FIGURE 2 HERE]}

Figure 2. Scatterplot of Content Scores and ESP Grades

Simple linear regression showed a statistically significant relationship between ESP grades and content scores $(\beta=0.42 . \mathrm{F}(1,144)=84.4, \mathrm{p}<0.001 * * *)$. Therefore, content scores increased by 0.42 for every point increase in ESP grade. The $\mathrm{R}^{2}$ value was 0.365 , so $36.5 \%$ of the variance in content scores can be explained by a model containing only ESP grades (see Table 5). Table 5 also presents the standardized Beta value $(\beta=0.61)$, which indicates that for every one-standard deviation increase in ESP grades $(\mathrm{SD}=10)$, content scores increased by 0.61 standard deviations. Thus, ESP grades scores statistically significantly predicted content scores.

\section{[PLEASE INSERT TABLE 5 HERE]}

Table 5. Linear Regression Output: ESP Grades and Content Scores

\begin{tabular}{|c|c|c|c|c|c|c|}
\hline & $\Delta R^{2}$ & $B$ & $S E B$ & Standardized $\beta$ & $t$ value & $p$ value \\
\hline Constant & 0.365 & 39.62 & 3.65 & & 10.84 & $<0.001 * * *$ \\
\hline ESP Grades & & 0.412 & 0.04 & 0.61 & 9.18 & $<0.001^{* * *}$ \\
\hline
\end{tabular}




\section{To what extent do motivation, academic language skill (ESP), and L2 proficiency (TOEIC) predict success in EMI?}

In order to answer the fourth research question, all predictor variables were put into one statistical model in order to explore variance explained in the outcome variable (content scores). A multiple linear regression was calculated to predict success in EMI based on English proficiency (TOEIC scores), academic language skill (ESP grades), and motivation (Ideal L2 Self). The scatterplot of standardized predicted values verses standardized residuals showed that the data met the assumptions of homogeneity of variance and linearity, and the residuals were approximately normally distributed. A significant regression equation was found $\left(\mathrm{F}(3,142)=39.8, p<0.001^{* * *}\right)$, with an $\mathrm{R}^{2}$ of 0.445 (see Table 6).

\section{[PLEASE INSERT TABLE 6 HERE]}

Table 6. Multiple Regression Output: TOEIC, ESP, Motivation and Content Scores

\begin{tabular}{|c|c|c|c|c|c|c|}
\hline & $\Delta R^{2}$ & $B$ & $S E B$ & Standardized $\beta$ & $t$ value & $p$ value \\
\hline Constant & 0.445 & 32.18 & 3.88 & & 8.28 & $<0.001^{* * *}$ \\
\hline TOEIC & & 0.020 & 0.004 & 0.333 & 4.86 & $<0.001^{* * *}$ \\
\hline ESP Grades & & 0.329 & 0.047 & 0.475 & 6.99 & $<0.001^{* * *}$ \\
\hline Motivation & & -0.223 & 0.412 & -0.035 & -0.54 & 0.59 \\
\hline
\end{tabular}

Table 6 further illustrates that participants' Content Scores increased by 0.02 for every one percentage point increase in TOEIC score, increased by 0.33 for every one percentage point increase in ESP Grade, and decreased by 0.22 for every point increase on the motivation scale. To conclude, motivation was not a statistically significant predictor of success in EMI, however, both TOEIC scores and ESP grades were significant predictors of content scores achievement when all variables were considered.

\section{How do students perceive success in EMI?}

In the quantitative analysis, success in EMI was operationalized in terms of content exam scores, whereas in our qualitative analysis of interview data, we sought to explore students' perceptions of success. Although examination success underpinned participants' visions of accomplishment, the interview data highlighted success in more nuanced terms. Patterns in interview data indicated that success primarily centred on (1) lecture comprehension; (2) final grades; (3) English proficiency development, and (4) long-term career advancement.

All of the seven students interviewed felt a strong desire to achieve the same level of lecture comprehension in their English taught courses as compared to their Japanese-taught courses. Generally, students did not want to sacrifice the quality of their content learning due to the medium of instruction, as illustrated by the following interview excerpt:

'My goal of EMI is to be able to understand English lectures completely. I'm attending the EMI programme to acquire new disciplinary knowledge. I wouldn't like to feel disadvantaged just because I'm learning in English.' (Fumizaki, high English proficiency, high content score)

Similarly, other students saw their own knowledge advancement through English as a key measure of their success, but interview data further revealed that this was not a goal easily achieved. Despite a desire to maintain the quality of their learning, all 
interviewees felt somewhat disadvantaged to learn their academic subject in their second language, which affected their learning. One interviewee stated that while he had 'relatively high' conversational English skills due to his childhood experiences living in Australia, 'studying my major [business] in English slows down my content understanding compared to Japanese because of many technical words I don't know' (Hishinuma, high English proficiency, high content score). Lower proficiency students revealed further barriers to success, such as Aoki, who stated that 'When listening to lectures and reading textbooks, I sadly still have to translate every single sentence from English into Japanese in my head.' (low English proficiency, low content score). Interview data generally supported a connection between proficiency and academic performance: higher proficiency students were inhibited by technical vocabulary, but lower proficiency students had underlying comprehension difficulties.

Some students explicitly saw English language development as a further outcome of success for their EMI studies, hoping to gain not only content knowledge, but also to improve their English language proficiency. Aoki (low English proficiency, low content score) explicitly stated that her personal aim in the course was to improve her English listening and reading skills. A further student Yujima (high English proficiency, high content score) aimed to improve 'both English and business knowledge at the same time'. Hirota (middle English proficiency, high content score) stated that successfully learning content in English would place him at an advantage in the future:

'I want to work globally using English in the future. I of course take longer time to study in English than Japanese, but I still think it's worth studying in English because in the long term, I don't need to re-learn all the business terminologies in English in order to talk with my future international colleagues in English.'

Thus, students in general saw language proficiency development as a subsidiary success measure of participating in English taught courses, with some linking proficiency and knowledge acquisition to future employment goals. In this way, student perceptions of success appear to broadly align with the driving forces of EMI discussed earlier in this paper.

In contrast to the quantitative results, which showed no effect of motivation on success in EMI, students explicitly drew connections between their own language learning motivation and content score attainment. All of the students interviewed $(n=7)$ stated that the English medium nature of the course motivated them to study more compared to studying in Japanese. Yujima (high English proficiency, high content score) stated, 'I much prefer studying through English to Japanese because my grades become better in EMI'. Similarly, another student stated:

'When I take English medium classes, I tend to achieve higher final grades because I study more in English than Japanese. When I learn in Japanese I don't feel motivated to study at all because I feel like I can understand my lectures and textbooks effortlessly and learning becomes boring. I end up not studying enough and getting very bad final grades in JMI courses.' (Hishinuma, high English proficiency, high content score)

Thus, while the quantitative analysis revealed no significant connection between performance and motivation, the students themselves did. This may, however, be the result of selection bias, that is of motivated students self-selecting to take part in the interviews. It may also indicate that other dimensions of motivation (e.g. the more instrumentally focused Ought-to L2 Self, see Kormos and Csizér 2008, or non-language- 
oriented motivation) are more important in the EMI context. Overall, our findings suggest that EMI motivation warrants further investigation in future research.

\section{Discussion: Implications for higher education and future research}

As the quantitative results showed, English language related variables were the strongest predictors of success in EMI. This result indicates that one way to increase students' chances of success in English taught programs is to support growth in students' general English language proficiency. Our results also show that lower proficiency students are at a disadvantage compared to their higher proficiency counterparts in terms of content score attainment - a point further exemplified by the qualitative data. This result echoes similar findings in the Japanese context, which found that students above a threshold of language proficiency of IELTS 6.5 experienced fewer challenges learning content through English than those below the threshold (Author and Author 2018).

The results of our study, however, would not support the introduction of language entry requirements for EMI courses in this context. The quantitative results also showed students from all levels of proficiency were able to pass the course, and the qualitative data revealed that students saw benefits to studying through English, which outweighed the costs to their GPA. Rather than limiting access, lower proficiency students might benefit from more language support while undertaking study. As ESP grades were more strongly correlated with success than general proficiency, the results of the current study suggest this language support might best be operationalized in the form of specific classes which target the vocabulary, language, and academic needs associated with the subject area.

\section{Motivation and success in EMI}

The fact that motivation was not significantly correlated with success, but was indicated as important to students in the qualitative data suggests further investigation of this relationship is needed. Even though the Ideal L2 self has been shown to be the more robust measure of motivation in explaining success in language learning (Dornyei and Ryan 2015), this did not transfer to this EMI context. This finding contradicts EMI research in other contexts (Lasagabaster 2016) by showing that the potency of this construct did not translate into higher achievement in terms of content scores. As motivation still seems to be a central driving force for many students, alternative motivational constructs might prove to be better predictors of success for content learning and should be explored in future studies.

\section{Alternative perceptions of success}

Although studies have shown that studying through a second language is not as effective as through one's first language (e.g. Klaassen and De Graaff 2001), the current evidence suggests that there are a number of other perceived benefits of EMI, which may compensate for the potential 'cost' to students' grades. In this study, students saw success in EMI as also maintaining the quality of content learning vis-à-vis successful lecture comprehension, improving English language knowledge, and enhancing longterm career success. Future studies should, therefore, widen the scope of their measures of success to explore whether EMI does, for example, lead to better career outcomes for students. Similarly, while some studies (e.g. Aguilar Mūnoz 2014) have provided somewhat bleak results on the effects of EMI on language proficiency development, further research is needed to provide a more nuanced understanding of how EMI develops subject-specific language knowledge, if at all. 


\section{Conclusion}

While English language related variables were shown to be the strongest predictors of success in EMI, this current study is limited in how this proficiency was measured, opening the scope to further research. While we used TOEIC as the standardized measure made available to us, a more nuanced measure of the academic and language skills associated with EMI and business knowledge may yield different results. Furthermore, the students in the study all were majors of international business, which is described as an 'internationally oriented' subject (Macaro 2018). As each EMI context is unique, other subject areas and universities may yield different profiles of students, and reveal other issues at the nexus of language, motivation and success.

\section{References}

Aguilar, M., and C. Mūnoz. 2014. The effect of proficiency on CLIL benefits in Engineering students in Spain. International Journal of Applied Linguistics 24(1): 1-18.

Airey, J. 2012. "I don't teach language." The linguistic attitudes of physics lecturers in Sweden. AILA Review 25: 64-79.

Aizawa, I., and H. Rose. 2018. An analysis of Japan's English as medium of instruction initiatives within higher education: the gap between meso-level policy and micro-level practice. Higher Education. doi: 10.1007/s10734-018-0323-5

Alderson, J. C., L. Nieminen, and A. Huhta. 2016. Characteristics of weak and strong readers in a foreign language. The Modern Language Journal 100(4): 853-879.

Başıbek, N., M. Dolmacı, B. C. Cengiz, B. Bür, Y. Dilek, and B. Kara. 2014. Lecturers' Perceptions of English Medium Instruction at Engineering Departments of Higher Education: A Study on Partial English Medium Instruction at Some State Universities in Turkey. Procedia - Social and Behavioral Sciences 116: 18191825.

Brinton, D., M. A. Snow, and M. B. Wesche. 2003. Content-based second language Instruction. Ann Arbor: University of Michigan Press.

Chang, J.-Y., W. Kim, and H. Lee. 2017. A language support program for Englishmedium instruction courses: Its development and evaluation in an EFL setting, International Journal of Bilingual Education and Bilingualism 20(5): 510-528. doi: 10.1080/13670050.2015.1080658

Cho, Y., and B. Bridgeman. 2012. Relationship of TOEFL iBT scores to academic performance: Some evidence from American universities. Language Testing, 29(3): 421-442. doi:10.1177/0265532211430368

Costa, F. 2012. Focus on form in ICLHE lecturers in Italy. Evidence from Englishmedium science lectures by native speakers of Italian. AILA Review 25: 30-47. doi: 10.1075/aila.25.03cos

Dafouz, E., M. Camacho, and E. Urquia (2014). 'Surely they can't do as well': a comparison of business students' academic performance in English-medium and Spanish-as-first- language-medium programmes. Language and Education 28 (3): 223-236.

Dimova, S., A. K. Hultgren, and C. Jensen. 2015. English-medium instruction in

European higher education: review and future research. In: S. Dimova, A. K. Hultgren, and C. Jensen (eds.) English-Medium Instruction in European Higher Education. Language and Social Life, 317-324. Berlin: De Gruyter Mouton.

Dörnyei, Z., and S. Ryan. 2015. The psychology of the language learner revisited. New York: Routledge. 
Doiz, A., D. Lasagabaster, and J. M. Sierra. 2014. CLIL and motivation: The effect of individual and contextual variables. The Language Learning Journal 42(2): 209224.

Evans, S., and B. Morrison. 2011. Meeting the Challenges of English-Medium Higher Education: The First-Year Experience in Hong Kong. English for Specific Purposes 30(3): 198-208.

Galloway, N., J. Kriukow, and T. Numajiri. 2017. Internationalisation, higher education and the growing demand for English: an investigation into the English medium of instruction (EMI) movement in China and Japan. London: British Council.

Graham, J. G. 1987. English Language Proficiency and the Prediction of Academic Success. TESOL Quarterly 21(3): 505-521. doi: 10.2307/3586500

Hair, J., W. Black, B. Babin, and R. Anderson. 2010. Multivariate data analysis: A Global Perspective. Upper Saddle River, NJ: Person Education Inc.

Hamid, M. O., H. T. M. Nguyen, and R. B. Jnr. Baldauf. 2013. Medium of instruction in Asia: Context, processes and outcomes. Current Issues in Language Planning 14: 1-15.

Hill, K., N. Storch, and B. Lynch. 1999. "A comparison of IELTS and TOEFL as predictors of academic success". In R. Tulloh (Ed.), IELTS research reports (Vol. 2, pp. 62-73). Canberra: IELTS Australia.

Hu, G., L. Li, and J. Lei. 2014. English-medium instruction at a Chinese University: Rhetoric and reality. Language Policy 13(1): 21-40.

Huong, T. 2001. The predictive validity of the International English Language Testing System (IELTS) test. Post-Script 2(1): 66-94.

Iwaniec, J. 2014. Motivation of pupils from southern Poland to learn English. System 45: $67-78$.

Johnson, P. 1988. English language proficiency and academic performance of undergraduate international students. TESOL Quarterly 22: 186-168. doi: $10.2307 / 3587070$

Johnson, R. K., and M. Swain. 1997. Immersion education: international perspectives. Cambridge: Cambridge University Press.

Kerstijens, M., and C Nery. 2000. Predictive validity in the IELTS test: A study of the relationship between IELTS scores and students' subsequent academic performance. IELTS Research Reports 3: 85-108.

Klaassen, R. G., \& De Graaff, E. (2001). Facing innovation: preparing lecturers for English-medium instruction in a non-native context. European Journal of Engineering Education 26(3): 281-289. https://doi.org/10.1080/03043790110054409

Kormos, J., and K. Csizér. 2008. Age-related differences in the motivation of learning English as a foreign language: Attitudes, selves, and motivated learning behavior. Language learning 58(2): 327-355.

Krausz, J., A. Schiff, J. Schiff, and J. V. Hise. 2005. The impact of TOEFL scores on placement and performance of international students in the initial graduate accounting class. Accounting Education: An International Journal 4(1): 103111. doi:10.1080/0963928042000256671

Lasagabaster, D. 2016. The relationship between motivation, gender, L1 and possible selves in English-medium instruction. International Journal of Multilingualism 13(3): 315-332. 
Leaver, B. L., and S. B. Stryker. 1997. Content-based instruction in foreign language education: models and methods. Washington, D.C.: Georgetown University Press.

Light, R. L., M. Xu, and J. Mossop. 1987. English proficiency and academic performance of international students. TESOL Quarterly 21(2): 251-261. doi: $10.2307 / 3586734$

Lin, L. H. F., and B. Morrison. 2010. The Impact of the Medium of Instruction in Hong Kong Secondary Schools on Tertiary Students' Vocabulary. Journal of English for Academic Purposes 9(4): 255-266.

Macaro, E., S. Curle, J. Pun, J. An, and J. Dearden. 2018. A Systematic Review of English Medium Instruction in Higher Education. Language Teaching 51(1): 3676.

Macaro, E. 2018. English Medium Instruction. Oxford: Oxford University Press.

Martirosyan, N. M., E. Hwang, and R. Wanjohi. 2015. Impact of English Proficiency on Academic Performance of International Students. Journal of International Students 5(1): 60-71.

Ministry of Education, Culture, Sports, and Technology (MEXT). 2015. Heisei 25 nendo no daigaku ni okeru kyouiku nai you tou no kaikaku joukyou ni tsuite [About the state of affairs regarding university reforms to education in 2013]. Retrieved from http://www.mext.go.jp/a_menu/koutou/daigaku/04052801/_icsFiles/ afieldfile/2016/05/12/1361916_1.pdf

Morrison, K. and I. Lui. 2000. Ideology, Linguistic Capital and the Medium of Instruction in Hong Kong. Journal of Multilingual and Multicultural Development 21 (6): 471-486.

Pokay, P., and P. Blumenfeld. 1990. Predicting achievement early and late in the semester: The role of motivation and use of learning strategies. Journal of Education Psychology 82: 41-50.

Rose, H. and J. McKinley. 2018. Japan's English-medium instruction initiatives and the globalization of higher education. Higher Education 73(1): 111-129.

Stoynoff, S. 1997. Factors associated with international students' academic achievement. Journal of Instructional Psychology 24(1): 56-68.

Sheppard, E. and V. Ainsworth. 2017. English Impact: An evaluation of English language capability (Madrid, Spain). London: British Council.

Smit, U. 2010. CLIL in an English as a lingua franca (ELF) classroom: On explaining terms and expressions interactively. In C. Dalton-Puffer; T. Nikula and U. Smit (eds.). Language use and language learning in CLIL classrooms, 259-277. Amsterdam: John Benjamins.

Smit, U., and E. Dafouz. 2012. Integrating content and language in higher education: An introduction to English-medium policies, conceptual issues and research practices across Europe. AILA Review 25: 1-12. doi: 10.1075/aila.25.01smi

Taguchi, T., M. Magid, and M. Papi. 2009. The L2 motivational self system among Japanese, Chinese and Iranian learners of English: a comparative study. In Z. Dörnyei, and E. Ushioda (Eds.), Motivation, language identity and the L2 self, 66-97. Bristol: Multilingual Matters.

Turnbull, M., S. Lapkin, and D. Hart. 2001. Grade 3 immersion students' performance in literacy and mathematics: Province-wide results from Ontario (1998-99). The Canadian Modern Language Review 58: 9-26.

Wächter, B., and F. Maiworm, eds. 2014. English-taught programmes in European higher education: The state of play in 2014. Bonn: Lemmens Medien. 
Woodrow, L. 2006. Academic success of international postgraduate education students and the role of English proficiency. University of Sydney Papers in TESOL 1: 51-70.

Wongtrirat, R. 2010. "English language proficiency and academic achievement of international students: A meta-analysis." Doctoral dissertation, Old Dominion University. Retrieved from ProQuest Dissertations and Theses database (UMI No. 1434728).

Xu, M. 1991. The impact of English-language proficiency on international graduate students' perceived academic difficulty. Research in Higher Education 32: 557570 .

Yen, D. A., and J. Kuzma, J. 2009. Higher IELTS score, higher academic performance? The validity of IELTS in predicting the academic performance of Chinese students. Worcester Journal of Learning and Teaching 3: 1-7. 
Appendix A

'Ideal L2 self' items (adapted from Iwaniec [2014])

- I imagine myself comfortably reading books and articles in English.

- I imagine myself writing in English with ease.

- I imagine myself speaking English fluently.

- I imagine myself easily being able to follow what others myself easily being able to follow what others say to me in English. 